\title{
Analysis on Traditional Beauty of Korean Folk Costumes
}

\author{
Lin Shuyu
}

Lin Shuyu

\section{Keywords: Korean; Folk costumes; Traditional beauty; Analysis}

Abstract. Korean, as an important member of the 56 nationalities in our country, shaped its folk costumes based on the given geographical conditions, folk customs and its specific aesthetic idea. It combined the specific folk culture of Korean with the soul of history, both of which formed the costumes with distinct cultural connotation. Due to the history reasons, most of Koreans have a preference for nature, also making the Korean costumes mostly oriented in the natural colors. For example, the green representing the spring, the yellow representing the earth and the white representing the sky. And the national characteristics costumes can be formed by combining the rainbow-satin with these above colors. In general, this costume has an original style, bright color and superior fabric texture and pattern, which also makes the Korean costumes be more nationality-featured and charming.

\section{Introduction}

Recent years, people have paid more attention to the spiritual demand with the continuous development of the economy in our country. The costume, being the important carrier of culture and spirit, has been the focus in the instant research. Korean is a significant nation of our country, and the traditional beauty of its traditional costumes has gradually permeated the will of people. According to this, this paper aims at providing the strong support to the heritage and development by making a brief analysis on the Korean traditional folk costumes and dissecting the traditional beauty of Korean costumes from the aspects of modeling, color, pattern and texture.

\section{The brief introduction of the Korean costumes}

Most of Koreans live in the northeast frontier of our country, which is an important nation in our nationality and has its own culture, folk customs and character. And the Korean costume is relatively famous. Lots of Koreans are fond of the white clothes, which are the key factors expressing their characteristics of clear, tidy and simple but elegant. Many scholars endowed the Korean with the title of "White nation" based on this. Korean has three kinds of costumes. The first one is the robe that mainly refers to the costume wearing by the generations of princes and aristocrats, which will appear the discrepancy according to the difference of official position, while being the same in the aspect of overall pattern. The typist representative of the robe is Myeonbok that is made of silks and satins being the collar, shoulders with the dragon of color as well as the part of the cuff embroidering with fire and pheasant, etc. All of the most entire costumes adopt the satins to tailor, moreover, embroidering the substances rich of cultural meanings as the decoration in the front of the skirt, for example, the rice and the algae. The second one is Korean men's clothing whose upper outer garment is shorter in general, and the pants of which is long and loose. In addition, men also add a sleeveless jacket. Some of the Korean men's clothing is the robe. Most of those inherit the conventional costumes of literati and officialdom as well as the Confucian scholar. The last one is Korean women's dress whose main trait is the short garment matching with the long skirt. There will be a long cotton belt, and a bowknot will be placed under the right shoulder. Refer to the picture 1 for details. 
Picture 1 is Korean women's dress; men's clothes; robe in turn.
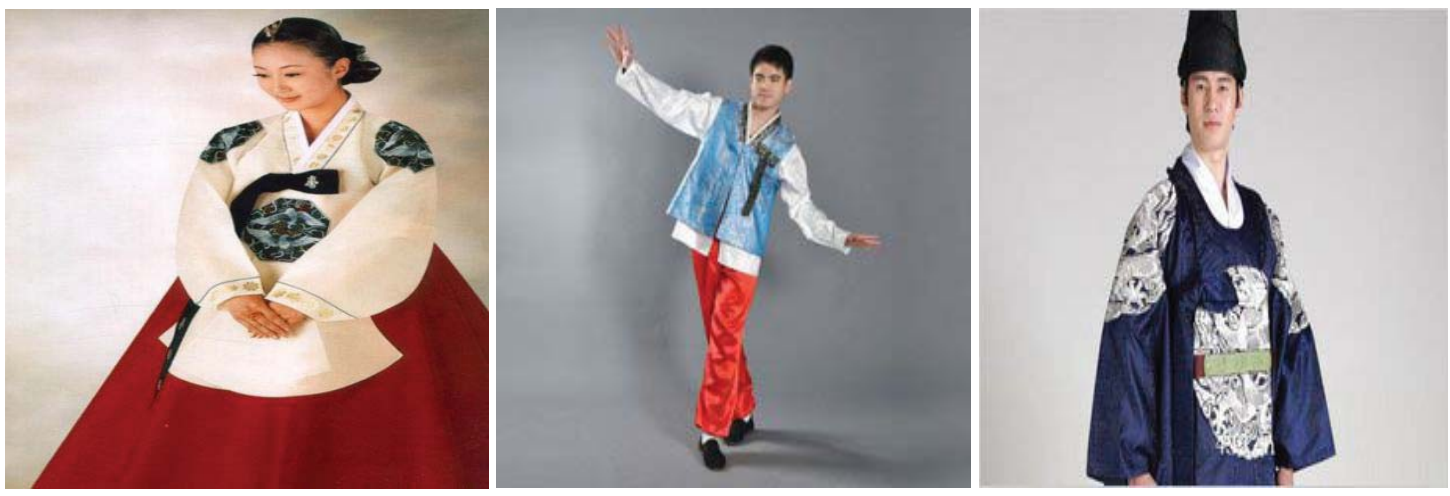

\section{The formation of Korean costumes}

The Korean nationality originates from the present Mongolia area and has gradually migrated to Korean peninsula since the first migration. Originally, most of Korean costumes were made of the fur, expressing the form of nomad national dress. And costumes have been changed little by little after the migration, gradually presenting the state of traditional clothes of ancient Asian countries. In specific, Korean costumes mainly experienced the following several periods. In the first place, when Korean has just migrated to Korean peninsula, costumes have gradually begun to transform into Han Chinese clothing as Korean is strengthening the communication with China little by little. Later, the culture of our nation has gradually permeated into the Korean peninsula in the Tang and Song dynasties, together with the traditional folk costumes, both of which make Korean costumes appear the forms of the garment upper matching the shirt under, the garment upper matching the pants under and cutting from top to bottom little by little. Along with the alternation of dynasties and the alteration of culture, Korean costumes have gradually converted to the robe and mostly based on the costumes of Ming during the Ming dynasty.

Combining with the self folk customs, the pattern of Korean robes above-mentioned has gradually appeared. Korean peninsula processed the second migration later and gradually entered into the Northeast China Region, becoming the vital nationality of our present nation. The Korean dress recognized by us in the present time is shaped by inheriting and developing the traditional costumes, as well as changing constantly.

\section{The analysis on the traditional beauty of Korean folk customs}

The analysis on the traditional beauty of folk customs usually starts from the following aspects. The first one is modeling that is a key factor of expressing the costumes aesthetics and the main method to manifesting the beauty. The next one is color matching which embodies the integrated culture of one nation, and the reasonable color matching can bring people tremendous visual impact. The third one is pattern, being the ornamentation of costumes, which is a key factor to expressing the dress aesthetics. The last one is the beauty of texture which is the foundation of the color pattern and modeling. If the costume materials are selected inferior, then the unique modeling and excellent color matching even cannot perfectly give play to the traditional beauty. Based on this, this paper makes the elaborated analysis on the traditional beauty of Korean folk costumes from the following aspects.

The analysis on the modeling beauty of Korean folk costumes . The analysis on the costumes modeling aesthetics is primarily divided into two parts, the first of which is corridors form. The corridors form of Korean folk costumes has a relatively distinct characteristic that it places the corridors form and smooth lines as the foundation of the costume modeling, which makes Korean folk costumes incisively and vividly embody its unique specialized style in the long river of history. The research on the corridors form of Korean folk costumes can express the typical national culture and the state beauty of nationality moral no matter it is from the corridors form aspect or the extended 
details. Taking the example of Korean folk women's clothes, we can see that all of the clothes present a cone triangle in the whole and give us the feeling that the upper part is thinner and the under part is thicker, which makes people feel comparatively stable and the posture of the dressed more petite. Next, with regard to the Korean culture, the sitting posture inherited by Korean women presents a cone triangle. When women sit down, they usually place their legs half-stand to make them raise the skirt. And the cone triangle will be shaped after they sat down. In addition, the part raised by the knees also forms the cone triangle through the meticulous observation. It is an unconscious form generated naturally over the inheritance for a long time, what's more, which is the representative of folk customs. Korean women have been the ideal models since ancient times, while the triangle is the most stable in the geometric figures. Combining the triangle with costumes indicates the domestic moral of Korean women. Figure 2 and figure 3 are the states of standing and sitting wearing Korean costumes.

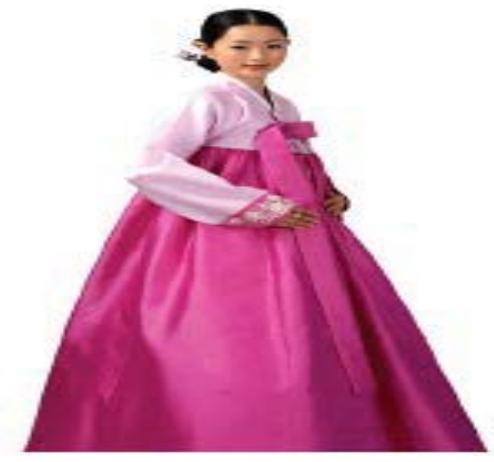

Fig.2 State of standing wearing Korean costumes

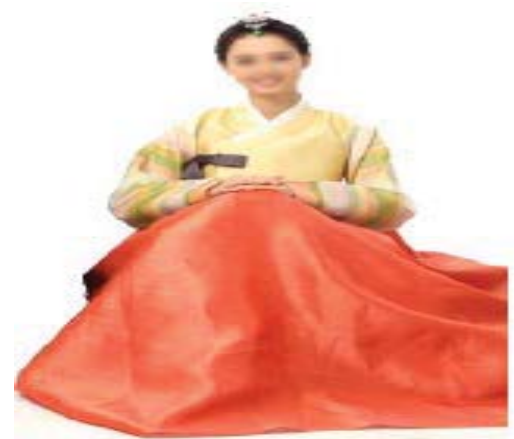

Fig.2 State of sitting wearing Korean costumes

The following one is the proportion which plays an important role in appearing the modeling beauty and costume traditional beauty. No matter a single clothing and accessory cannot incisively and vividly show the traditional beauty, so the proportion must be laid emphasis on. All of Korean conventional costumes are composed with the upper part and the under part. The upside of Korean women's clothes is garment, and the downside is skirt distinguished from the pants of the Korean men's clothes. Also, there are some costumes presenting an organic whole state up and down, for example, the robes usually worn by the Korean men. The proportion has been the focus of garment design since ancient times, especially in the women's dress. Affected by Han Chinese clothing Korean costumes, the upper outer garment of Korean costumes was mostly to the waist initially, then gradually the size of coat was shortened and eventually to the chest, which has been the classical proportion in the present. As can be seen from the above-mentioned figure, perfect proportion can also make Korean folk costumes more charming.

It turns out by synthesizing the above two points that the corridor form and the selection of proportion are the key factors guaranteeing the traditional beauty of Korean folk costumes. Perfect corridor form construction as well as the unique proportion selection is the main method to embody the charm of Korean folk costumes.

The analysis on the color beauty of Korean folk costumes. Color is the subject to express the costume vision and the main way to convey the innermost being of the wearer. In addition, Korean 
has a more particular aesthetic orientation at the color. For the Korean nationality, color bears the weight of folk customs and culture, which is the major carrier to embody their own feelings and the expressive theme of their belief. Korean folk costumes usually adopt the bigger color block to match rationally in the color matching, thus the characteristic clothes take shape with superior visual effect. Korean costumes have no much difference in the modeling, so the color has become the significant medium to embody the self-emotion for different people. Since ancient times, owing to the preference of nature and the relatively holy white in the Korea, it was called "White nation" by the people. Meanwhile, that the nationality reveres nature makes the costumes adopt colors representing nature. Then we dissect the traditional beauty of Korean folk costumes from the two aspects of white and colors. (1)White: Due to the preference of white in the Korean nationality, they hold the belief that white is on behalf of holy, tidy and simple but elegant. What's more, they think that white is a more indicative color. Therefore, it was called "White nation". The most typical custom of Korean is wearing the white clothes, living in the white house as well as eating the rice with nothing in ancient times. Even though the life is hard, the Korean will be in presence tidy and neat. To sum up, the reason why the people wear white clothes is plentiful. Some people believe that the Korean upholds the sun, because the light from the sun is white light. So they prefer to white. Another people think that Korean were not allowed to wear comparatively gorgeous clothes and the civilian only can be able to wear the white clothing in ancient times. While the Koreans who migrated to Northeast Chins region mostly are civilians, so they have a preference for white. Others say that the life of ancient Korean was harder and they didn't have the condition to dye clothes, which makes the white as the basis of most cloth. For a long time, it gradually grows up a convention inherited by the people. The write summarizes and has the idea that the reason of current people wearing the white little by little is that the white represents holy and neat, which is relatively close to the traditional belief of Korea and makes the people have a preference for white gradually. The other reason is the inheritance to the folk customs. (2) Colors: The most common color of Korean costumes is white. However, along with the influence of the external culture in the later period, together with the worship to nature of the nationality, the colors have been gradually used to the costumes and there exists the color matching of strong comparability in the meantime to form the color folk costume beauty. Nowadays, the Koreans are distinguished from the difference of their sex, age and status. In general, the yellow-red costume belongs to the maid. The red-green clothes have gradually been the standard costumes in the Korean conventional wedding, due to its bright color and intense shock feeling to the people. In addition, Koreans matches the rainbow colors which is difficult to be applied to shape the characteristic folk costumes. In the Korean costumes, rainbow colors mostly are applied to the sleeves of the maid, which bring people a more fresh beauty. And Koreans hold the belief that rainbow colors are lucky and can drive evil representing the health when applied to the costumes. The trait makes this kind of costume mostly be applied to the children and the aged, which wishes children grow up healthy and the aged many happy returns. The application of rainbow colors not only makes the costume luxury, but also deliveries the subtle aesthetics of color changes in temperature, which will brings people enormous visual impact and lead a person to endless aftertastes. Figure 4 is the color area comparison charts of Korean costumes. 

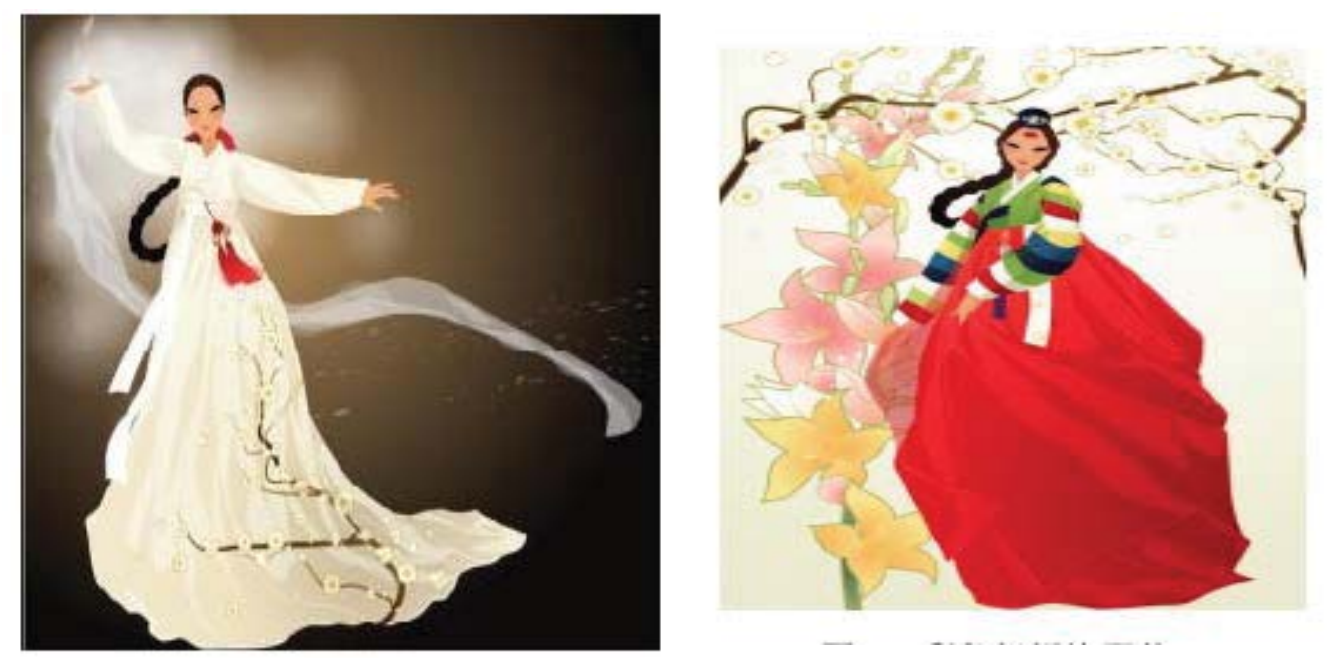

Fig.4 Color area comparison charts of Korean costumes.

The analysis on the pattern beauty of Korean folk costumes. Koreans always are fond of natural things and wearing some accessories. Of course, the pattern on the costume is essential. As one of the key factors of Korean folk costumes, the pattern is also a key factor to show the conventional aesthetics, same as the factors of modeling, color, etc. At the beginning, the Korean pattern is oriented with bilateral symmetry but has been gradually banned due to the few patterns and sole structure. Later, in order to give play to the trait of the worship to nature, the natural patterns have been gradually put into use, for example, the cloud representing the sky is widely applied to the Korean folk costumes. And the sun and the moon are the most common pattern in the Korean folk costumes. All of these patterns are regarded as the symbol of propitious and can drive evil. In the previous period of the reform and opening-up policy, some material patterns gradually were applied to the costumes because of the hard life of Koreans, for example, rice. They expected to bring themselves sufficient foods through the costumes. After the reform and opening-up policy, along with the continuous development of economical conditions, people's living standard has gradually enhanced, and the pattern of Korean folk costumes has gradually changed, for example, both of the chrysanthemums representing the lofty integrity and the bamboos representing the tenacious will are called the patterns of Korean folk costumes. Some people began to apply the animal patterns to it later, for example, the crane representing longevity, the kylin representing the lucky and the phoenix are called patterns. The deer, as one of the ten immortal animals, derives immortal grasses in the remote mountains and is regarded as immortal spirit beast, thus its pattern is endowed with the meaning of praying longevity. The bat has a strong ability of breeding, so it is regarded as the propitious animal and generally combined with the words of "blessing", "longevity" and "health and peace" on the costumes. The figure of tigers is always the animal image Koreans are fond of and its braveness is deemed as the symbol of the soldier, which is decorated on the chest and back. This indicates that the variety of Korean patterns has been gradually diversified. And with the diversified application of patterns as well as the color and the continuous layout of modeling, the traditional beauty of Korean folk costumes has been incisively and vividly expressed.

The analysis on the texture beauty of Korean folk costumes. The costume texture is the foundation of modeling and colors. If there is no better texture to make the costumes, the modeling and color will be of no use. In other words, texture is the main factor in the process of costumes and the basis of expressing the charm and traditional beauty. All of the selected materials for designing Korean costumes have their own particular characteristic and most of textures possess the traits of abstract aesthetics. In other words, it is the trait of possessing visual reality and artistic modeling. And the characteristics of these materials also make the Korean folk costumes become more and more diversified. In the first stage of Koreans migrating to our country, their traditional costumes mostly depend on the natural materials, and most of them make clothing with cotton. The demand of people has been gradually risen up with the rapid development of economy after the reform and opening-up policy, which makes of costume texture develop sharper and the building materials of Korean folk 
costumes more diversified. More and more fabric lining with softer touch sense have been used to the Korean folk costumes little by little, which also embodied the traditional beauty of Korean folk costumes incisively and vividly.

Because of the tougher life of Koreans initially, most people regard the natural materials as the formal element of folk costumes. Due to the white color of original linen productions, the initial Korean popular white clothes take up, which makes the linen be the most common costume lining at that time. Koreans give play to their intelligence in fully showing the hard trait of lining and form the starched modeling in the initial Korean folk costumes. But it makes the lining have its own limits that the lining is thinner and has a inferior extent to resisting the coldness. So Koreans have begun to exploit new material, namely the cotton, which has been the primary measure to resist the coldness in the winter owing to its superior sealing property. And in order to meet with the starched modeling, Koreans processed the lining to make it gradually appear the starched modeling and form the linear planarity. After the reform and open-up policy, the costume texture has been gradually updated, so Koreans have begun to apply the superior plasticity texture to the traditional folk costumes, for example, silks and satins, tough silks and artificial fibers, which increases the whole modeling sense of costumes and updates the change of corridor form of conventional folk costumes little by little. Along with the development of economy, the advancement of lining craft and the change of conventional corridor form, Korean traditional folk costumes have appeared new change. Besides, the use of semitransparent texture makes the line of body more clear and the traditional costumes have more subtle and virtual-real change. The advanced craft as well as the conventional folk costumes makes the Korean traditional costumes become more and more splendid, what's more, they make the conventional beauty deeply rooted in everyone's minds.

In short, the costume is the most significant factor in the current process of human development and the best carrier of conventional aesthetics. Therefore, the costume aesthetics is of era significance, which integrates the folk customs of different regions to costumes and make them be the esthetic traditional folk costumes that is the major trend of the development of present folk customs. Just like the Korean traditional costumes, they perfectly embody not only their own culture, but also the national aesthetics. In addition, it is the most effective form representing the Korean traditional beauty.

The analysis on the traditional beauty of Korean folk costumes. The total analysis on the traditional beauty of Korean folk costumes needs to proceed from the two aspects, the first of which is the external formal beauty, namely the beauty we can directly experience with sense organs as well as a kind of visual impact. The next one is the internal formal beauty, in which the beauty is not able to directly been appreciated with sense organs but needs the furthermore dissection to understand its spiritual culture in order to realize the traditional beauty.

The external formal beauty of traditional beauty. The external formal beauty of costumes mainly means the first impression information with organs during the contact of people, which is vital for the costume and the key factor of deciding the destination of costumes. As can be seen from the above picture, Korean women's clothes are tied in the waist with a relatively wide ribbon in colors or white, of which the jacket mostly is about to the chest, the dress presents the state of cone triangle and the skirt directly touches the ground or a little higher. The dress usually presents the cupped state to show the sense of volume. Besides, the condition of skirt can be adjusted with the ribbon tying the waist, which is helpful to make different modeling and express the entire perfect form of bodies. What's more, most skirts of Korean folk costumes are not tailored so that skirts can be adjusted properly and placed with varieties of styles to augment different kinds of aesthetics.

Some forms behavior more solemn giving people an elegant traditional beauty, while some forms show a relatively free form giving people a lightsome traditional beauty. The continuous change of the straight and curve lines is also the unique trait of Korean folk costumes. Korean folk costumes mostly convey a sense of volume and its lines are the dynamic streamlines along with the change of volume. The lines not only include the fixed external corridor lines but also the natural curves of bodies. The connection of $\mathrm{V}$ collar and the ribbon is one of the characteristics of Korean folk 
costumes. The organic connection of both sides forms the unique conventional beauty of folk costumes, as seen in figure 5 .
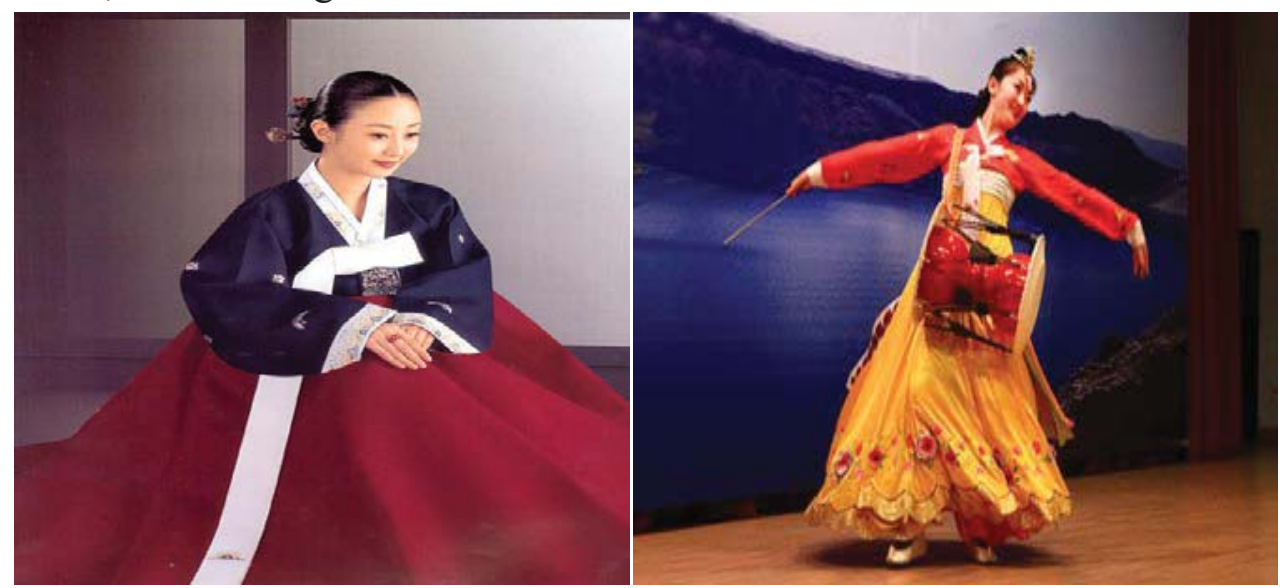

Fig.5 Examples of folk costumes

The internal formal beauty of traditional beauty. The traditional beauty of Korean folk costumes not only includes the external beauty with varieties of forms, but also has the characteristic internal beauty that mainly regards the costume as the carrier and conveys the mental power through the costumes. The inner beauty or clown can be judged through the ordinary communication and behaviors. Koreans adore nature and have an ardently love for nature, together with the education and guidance of Confucianism, both of which make Koreans attach great importance to their own appearance and content. What's more, the character of Korean is strong and firm, which forms a sharp contrast with the soft folk costumes. The costume and the character build the trait of this nationality, namely the soft appearance but the firm internal, which contributes to the relatively typical internal traditional beauty.

Korean folk costumes strive for the biggest until converting it, so that the body can be entirely mingled with the costume of which the curve covers the curve of the body, constructing the sense mixed the visual with real. And the beauty will be formed when Koreans wear folk costumes, which will present the beauty of body that is combined the dynamic and static. Korean folk costumes mostly are oriented of the simple style that has formed the present cone triangle state recognized by us through the more exaggerated construction in order to embody the aesthetics better. As can be seen from the above women's dress, the skirt extends from the chest and is raised up by the bustle to embody the sense of volume. When the wearer is still, it gives people an elegant and noble beauty that is the static beauty from the professional aesthetic. When the wearer swings, it will bring people a light and free aesthetic feeling that is the dynamic beauty from the professional aesthetic. On the whole, Korean folk costume is the combination of the dynamic and static, which can be incisively and vividly embodied on the typical drum dance of Korean nationality. In this drum dance, the dancer gets the hang of the rhythm properly though the motion of knees and moves the skirt that has enormous volume via the frequency change of breath. It makes the skirt appear the elegant state, and the audience will gradually be brought into the light and free aesthetics. Observing from the entirety, we can find that the dancer conveys the noble and elegant beauty. Besides, it embodies the internal beauty of Koran folk costumes that the jacket is narrow and small while the cuff is loose, as well as the relatively wide waist ribbon. Meanwhile, the smooth and tidy clothes body and skirt adding the organic combination of $\mathrm{V}$ collar and white lines construct the visual effect with the firmness and softness.

And the front jacket differing in length forms the elegant feeling during the process of rhythm, which makes the unique internal aesthetics of "the mixture of static and dynamic" appear in the whole costume. In addition, it vividly embodies the aesthetic feeling of dynamic and static as well as the inner charm of Korean folk costumes. 


\section{Conclusion}

To sum up, Korean folk costumes is of great characteristic and able to give play to the conventional aesthetics incisively and vividly from the two aspects of dynamic and static. Therefore, only by gradually inheriting and developing folk costumes can the traditional beauty stay in the heart of people, the tremendous efforts be made to the further development of aesthetic tendency of people and strong support be provided for the promotion of folk costume culture.

\section{References}

[1] Lili Qin. A Brief Analysis on the Traditional Beauty of Korean Folk Costumes [J]. Jiannan Literature (classical teaching), 2013, 02: 189.

[2] Fushi Shen. A Brief Analysis on the Traditional Beauty of Korean Folk Costumes [J]. National Forum, 2005, 12: 41.

[3] Jianbo Zhu. The Source for Features and Folk-customs of Korean Folk costumes [J]. The academic journal of Northeast University of Electric Power, 2006, 05: 102-104.

[4] Rui Wang. The Research of Korean Costume Art [J]. Heilongjiang National Series, 2014, 03: 131-136. 